\title{
Análise Econômica de Sistemas de Produção para Recria de Bezerras de Corte
}

\author{
Alcides Pilau', Marta Gomes da Rocha², Davi Teixeira dos Santos ${ }^{3}$
}

\begin{abstract}
RESUMO - Objetivou-se com a análise econômica de sistemas de recria de bezerras de corte em pastagem de aveia preta (Avena strigosa Schreb) e azevém (Lolium multiflorum Lam.) determinar a relação entre desempenho animal e retorno econômico. Os dados analisados foram gerados em quatro experimentos de pastejo conduzidos na Universidade Federal de Santa Maria, RS. Foram avaliados os custos de produção, produção animal e margem bruta. Os experimentos foram realizados nos anos de 1998 a 2001. Os sistemas de alimentação foram - ANO 1: STP- suplementação dos animais durante todo período da pastagem; SAS- suplementação dos animais até setembro; SS- sem suplementação; ANO 2: níveis de suplementação energética de 0; 0,7 e 1,4\% do peso vivo (PV); ANO 3: AAS- aveia + azevém + suplementação; AAN- aveia + azevém $+300 \mathrm{~kg} / \mathrm{ha}$ de nitrogênio; AAL - aveia + azevém + trevo vesiculoso $($ Trifolium vesiculosum Savi); ANO 4: DFB - disponibilidade de forragem baixa; DFA - disponibilidade de forragem alta; DFBS- disponibilidade de forragem baixa e suplementação; DFAS - disponibilidade de forragem alta e suplementação. Foram utilizadas bezerras de corte da raça Charolês e suas cruzas com Nelore, com idade inicial de oito meses. Os ganhos de peso vivo e os custos de produção dos sistemas de alimentação variaram de 324 a 671 e de 267 a $632 \mathrm{~kg}$ /ha de peso vivo (PV), respectivamente. As maiores margens brutas foram obtidas em 1999, $148 \mathrm{~kg} /$ ha de PV, com a utilização exclusiva da pastagem e $137 \mathrm{~kg} / \mathrm{ha}$ de PV, com uso de suplementação. O preço pago pelo $\mathrm{kg}$ de suplemento deve se situar na faixa de 0,05 a $0,07 \mathrm{~kg}$ de PV para tornar seu uso economicamente viável em relação ao uso exclusivo da pastagem.
\end{abstract}

Palavras-chave: aveia, azevém, recria de fêmeas, retorno econômico, suplementação

\section{Economic Analysis of Production Systems for Rearing of Beef Heifers}

\begin{abstract}
The aim of the analysis systems for rearing of beef heifers in black oats (Avena strigosa Schreb) and annual ryegrass (Lolium multiflorum Lam) pasture was to determine animal performance and economic relationships. Data were analyzed from four grazing trials performed at the Federal University of Santa Maria, RS. Production costs, animal production and gross margin were evaluated. The trials were conducted from 1998 to 2001. The feeding systems were YEAR 1: STP- animal supplementation during entire pasture cycle; SAS - supplementation of animals until September; SS - no supplementation; YEAR 2: energy supplementation levels of $0, .7$, and $1.4 \%$ of live weight (LW); YEAR 3: AAS- oats + ryegrass + supplementation; AAN - oats + ryegrass + $300 \mathrm{~kg} / \mathrm{ha}$ of nitrogen; AAL - oats + ryegrass + arrowleaf clover (Trifolium vesiculosum Savi); YEAR 4: DFB - low forage availability; DFA - high forage availability; DFBS - low forage availability and supplementation; DFAS - high forage availability and supplementation. Beef heifers of the Charolais breed and their crosses with Nellore with initial age of eight months were used. The live weight (LW) gain and feeding systems production costs ranged from 324 to 671 and from 267 to $632 \mathrm{~kg} / \mathrm{ha}$ of $\mathrm{LW}$, respectively. The greater gross margin was obtained in $1999,148 \mathrm{~kg} / \mathrm{ha}$ of $\mathrm{LW}$, only in pasture and $137 \mathrm{~kg} / \mathrm{ha}$ of $\mathrm{LW}$, with supplementation. The price paid for $\mathrm{kg}$ of supplement must be from .05 to $.07 \mathrm{~kg}$ of $\mathrm{LW}$ to be economically viable in relation to the use of exclusive pasture.
\end{abstract}

Key Words: annual ryegrass, economic return, oats, rearing of heifers, supplementation

\section{Introdução}

O desempenho reprodutivo é um grande limitante da produtividade do rebanho de corte gaúcho. Para um rebanho de 13.482 .053 cabeças, há um percentual de $31,6 \%$ constituído por fêmeas em recria (Anualpec, 2000). A área pastoril do estado do Rio Grande do Sul é de 11.910.000 ha de pastagem nativa e 1.093.000 ha de pastagens cultivadas (Moraes et al., 1995). A pastagem nativa suporta, durante o ano, em média, uma novilha/ha; estima-se, então, que aproximadamente 4 milhões de ha são destinados a animais de baixa produtividade dentro do sistema de cria e recria.

Bezerros e bezerras em recria são as categorias animais mais sensíveis aos períodos de escassez alimentar. Existe um volume razoável de trabalhos em sistemas de alimentação para esta categoria animal, visando a diminuição da idade ao primeiro acasalamento e redução da idade de abate dos novilhos e proporcionando condições às fêmeas de atingi-

\footnotetext{
1 Zootecnista. Aluno do PPGZ - Departamento de Zootecnia - UFSM. Bolsista CAPES. E.mail: alcidespilau@bol.com.br

2 Eng.-Agr. Dra. Profa. Adjunto do Departamento de Zootecnia - UFSM. E.mail: tata@via-rs.net

3 Zootecnista. Aluno do PPGZ - Departamento de Zootecnia - UFSM. Bolsista CAPES. E.mail: daviteixeira@hotmail.com
} 
rem peso adulto antes do primeiro parto. As implicações econômicas destas pesquisas, no entanto, raramente são publicadas e é a repercussão econômica de uma nova tecnologia no sistema de produção que determinará a sua adoção por parte dos produtores rurais.

A busca por sistemas de produção para acasalamento de novilhas aos 24 ou mesmo aos 14 meses requer a utilização de um planejamento alimentar adequado no período hiberno-primaveril. Sistemas que fazem uso de tecnologia mais intensiva apresentam melhores resultados econômicos quando comparados ao sistema 'tradicional' (Pötter et al., 2000).

A recria de fêmeas bovinas exclusivamente em pastagens cultivadas de inverno apresenta retorno econômico satisfatório (Roso \& Restle, 2000), independentemente dos benefícios indiretos proporcionados sobre as demais categorias animais do rebanho. Práticas de suplementação dos animais podem ser utilizadas para potencializar o seu desempenho biológico. O emprego da suplementação, ainda, permite que os animais atinjam o limite genético para ganho de peso, que provavelmente nunca é atingido em animais consumindo exclusivamente pastagens (Poppi \& McLennan, 1995). Do ponto de vista econômico, estas práticas devem estar enquadradas dentro do sistema produtivo de forma a elevar a sua lucratividade.

$\mathrm{O}$ acréscimo de nova tecnologia representa custo adicional por unidade produzida, os custos variáveis, e, quando apresenta bons resultados biológicos, amortiza os custos fixos constituídos por gastos com serviços administrativos, impostos, depreciações de máquinas e implementos, aumentando a lucratividade da empresa. Novas tecnologias encontram restrições à sua adoção, quando aumentam os custos diretos da empresa rural. Muitas vezes, os resultados produtivos não cobrem estes custos, devido à má escolha da alternativa a ser usada ou por sua utilização ineficiente.

Trabalhos de pesquisa, muitas vezes, buscam otimizar o potencial biológico do sistema de produção empregado, não sendo a sua viabilidade econômica o fator determinante para avaliar o sucesso dos resultados obtidos. O objetivo deste trabalho foi associar e discutir a produção animal na recria de fêmeas de corte e o desempenho econômico de quatro experimentos realizados em anos subseqüentes, em uma mesma área experimental, envolvendo pastagem cultivada de inverno e suplementação energética aos animais.

\section{Material e Métodos}

Os dados analisados foram oriundos de resultados biológicos obtidos em quatro experimentos realizados em área pertencente ao Departamento de Zootecnia da Universidade Federal de Santa Maria (UFSM), no período de inverno/primavera dos anos de 1998 a 2001.

Os experimentos realizados avaliaram os sistemas alimentares detalhados a seguir, todos em pastagem cultivada de aveia e azevém, em sistema de pastejo contínuo e taxa de lotação variável. Os animais utilizados foram fêmeas bovinas da raça Charolês e suas cruzas com Nelore, com idade média inicial de oito meses, pertencentes a um mesmo rebanho. Os pesos iniciais dos animais testes foram 117, 204, 180 e $164 \mathrm{~kg}$ nos anos de 1 a 4, respectivamente.

ANO 1 - STP- animais em pastejo recebendo suplementação energética durante todo período de utilização da pastagem; SAS- animais em pastejo recebendo suplementação energética até o final de setembro; SS- sem suplementação. O suplemento utilizado foi o grão de sorgo moído, fornecido na proporção de 1\% do PV (Rocha et al., 2003a).

ANO 2 - T 0- animais exclusivamente em pastejo; T 0,7 - animais em pastejo recebendo suplementação de $0,7 \%$ do PV; T 1,4 - animais em pastejo recebendo suplementação de $1,4 \%$ do PV. O suplemento utilizado foi polpa cítrica + farelo de arroz $(1: 1)$ (Frizzo et al., 2003).

ANO 3 - AAS- animais em pastagem de aveia + azevém + suplementação energética; AAN- animais em pastagem de aveia + azevém $+300 \mathrm{~kg} / \mathrm{ha} \mathrm{de}$ nitrogênio; AAL- animais em pastagem de aveia + azevém consorciado com trevo vesiculoso (Trifolium vesiculosum Savi) cv. Yuchi. O suplemento utilizado foi grão de sorgo moído, na proporção de $1 \%$ do PV (Rocha et al., 2003b).

ANO 4 - DFB - animais em pastejo sob disponibilidade de forragem baixa; DFA - animais em pastejo sob disponibilidade de forragem alta; DFBS animais em pastejo sob disponibilidade de forragem baixa + suplementação energética; DFAS - animais em pastejo sob disponibilidade de forragem alta + suplementação energética. As disponibilidades de forragem baixa e alta foram de 1.200 e $1.500 \mathrm{~kg} / \mathrm{ha} \mathrm{de}$ matéria seca, respectivamente. O suplemento utilizado foi grão de sorgo moído, fornecido na proporção de 0,7\% do PV (Pilau et al., 2002).

Os dados de ganho médio diário (GMD), carga

R. Bras. Zootec., v.32, n.4, p.966-976, 2003 
animal (CA) e ganho de peso vivo (GPV) foram submetidos à análise de variância e teste $\mathrm{F}$. Quando necessário, foi realizado o teste de comparação de médias, por meio do teste Tukey, em nível de $5 \%$ de probabilidade.

Para as avaliações dos custos de produção, foram utilizadas planilhas de cálculo Excel, versão 5.0, a partir do modelo proposto por Pötter (1998).

O levantamento de preços dos tratores, implementos agrícolas, sementes, fertilizantes, suplementos, salário mínimo rural e demais insumos foram obtidos em consultas a empresas da região de Santa Maria - RS, durante o mês de outubro de 2001. O preço do calcário foi estabelecido a partir do produto espalhado na lavoura, no município de Santa Maria, trazido de uma distância de $100 \mathrm{~km}$.

O metro linear de cocho foi calculado conforme o preço da dúzia de tábuas (2,5 polegadas) de $0,3 \times 4,2 \mathrm{~m}$ e diluído em três anos. $\mathrm{O}$ valor do beneficiamento da ração foi correspondente à taxa cobrada por cooperativas agrícolas da região, de $10 \%$ sobre o valor dos ingredientes. Nestes custos, foram incluídos: mão-de-obra no processamento, energia elétrica, desgaste das máquinas e transporte até a propriedade, em um raio de $100 \mathrm{~km}$.

O custo da mão-de-obra foi estabelecido a partir do salário mínimo rural, da Região da Campanha, RS, somado aos encargos sociais. O número considerado de horas trabalhadas foi de 220 horas mensais. Para os custos dos tratores, foram somados os gastos de depreciação, conservação, combustíveis, lubrificantes e mão-de-obra e, para os implementos, foram computados os custos de depreciação e conservação.

Os coeficientes técnicos empregados nas análises basearam-se nos 'material e métodos' dos quatro experimentos. $\mathrm{Na}$ área experimental, foi realizada uma aplicação de calcário de 5 t/ha, em 1996. O valor desta aplicação foi diluído nos custos dos cinco anos seguintes. $\mathrm{Na}$ área correspondente ao tratamento aveia + azevém + trevo vesiculoso (ANO 3), adicionaram-se mais $3 \mathrm{t} / \mathrm{ha}$ de calcário para elevar o pH do solo a 5,5, conforme laudo de análise de solo. O preparo do solo, no ANO 1, foi feito pelo sistema de plantio convencional. Nos anos seguintes, empregou-se o sistema de plantio direto com dessecação prévia da área. As discussões sobre os níveis de fertilidade foram a partir de análises de solo realizadas em abril de 1996 e 2001.

Na Tabela 1, são apresentadas as quantidades de sementes de aveia e azevém, adubação de base e adubação nitrogenada de cobertura nos quatro sistemas avaliados. As aplicações de nitrogênio foram todas na forma de uréia (45-0-0). No item "sistema de plantio", os custos considerados referem-se aos custos operacionais para o preparo da área e para semeadura e adubação.

Para determinação da quantidade de vermífugo fornecida em cada tratamento, a carga animal média foi dividida pelo peso médio dos animais. Obteve-se, dessa forma, a taxa de lotação média, a qual foi multiplicada pelo número de aplicações e pela quantidade de produto por animal. O sal comum foi fornecido à vontade e seu consumo médio, estimado em $50 \mathrm{~g} / \mathrm{animal} / \mathrm{dia}$. O total de sal fornecido foi calculado pela multiplicação da lotação média pelo consumo estimado e pelo período total de permanência dos animais na pastagem. As quantidades de suplemento foram calculadas utilizando a carga animal média multiplicada pelo período total de fornecimento da ração. Posteriormente, multiplicou-se pelo percentual do PV estabelecido para cada sistema. Os cochos para suplemento foram estimados em seis metros lineares por hectare nas dimensões de $0,3 \mathrm{~m}$ de altura x 0,6 m de largura.

Em todos os sistemas, foi adicionado um custo de arrendamento da terra de $2,58 \mathrm{~kg} / \mathrm{ha} / \mathrm{mês}$ de boi gordo, valor usual na região. Este valor foi ajustado para seis meses, período médio de utilização da área com pastagem cultivada de inverno. O custo por hectare dos sistemas foi calculado a partir da quantidade de $\mathrm{kg}$, litros ou horas de trabalho/ha, multiplicado pelo seu valor em reais. O valor em reais foi transformado em $\mathrm{kg}$ de PV, sendo o valor considerado

Tabela 1 - Quantidade de sementes de aveia e azevém, adubação de base e nitrogênio em cobertura, $(\mathrm{kg} / \mathrm{ha})$, utilizados em quatro sistemas de recria de fêmeas de corte. Santa Maria, 1998 a 2001

Table 1 - Quantity of oats and ryegrass seeds, fertilization and top seeded nitrogen, $(\mathrm{kg} / \mathrm{ha})$, in four rearing of beef heifers systems. Santa Maria, from 1998 to 2001

\begin{tabular}{lcccc}
\hline Ano & \multicolumn{2}{c}{$\begin{array}{c}\text { Sementes } \\
\text { Yeeds }\end{array}$} & $\begin{array}{c}\text { Adubação } \\
\text { Fertilization }\end{array}$ & $\begin{array}{c}\text { Nitrogênio } \\
\text { Nitrogen }\end{array}$ \\
\cline { 2 - 3 } & $\begin{array}{c}\text { Aveia } \\
\text { Oat }\end{array}$ & $\begin{array}{c}\text { Azevém } \\
\text { Ryegrass }\end{array}$ & & \\
\hline 1 & 85 & 30 & 200 & 130 \\
2 & 92 & 39 & 200 & 90 \\
3 & 87 & 43 & 300 & 150 \\
4 & 90 & 35 & 300 & 170 \\
\hline
\end{tabular}


de $\mathrm{R} \$ 1,45$, preço recebido pelos produtores pelo $\mathrm{kg}$ de PV de bezerras, em outubro de 2001. As comparações entre os sistemas alimentares foram todas realizadas considerando kg de PV como unidade.

A receita bruta foi obtida ao multiplicar o ganho de peso vivo/ha pelo preço do kg de PV. A margem bruta foi calculada a partir da diferença da receita bruta e do custo de produção, expressa em kg/ha de PV.

\section{Resultados e Discussão}

Na Tabela 2, encontram-se os custos/ha referentes à calagem e ao sistema de plantio, em porcentagem do valor total e $\mathrm{kg}$ de PV para os sistemas de produção avaliados. A calagem adicionou um custo de $20,69 \mathrm{~kg} / \mathrm{ha}$ de $\mathrm{PV}$, exceto quando foi utilizada uma leguminosa, trevo vesiculoso (Trifolium vesiculosum Savi), elevando este custo para $33,10 \mathrm{~kg} / \mathrm{ha}$ de PV. Quanto maior foi a utilização de recursos extras no sistema, visando aumento de produtividade, suplementação dos animais e/ou maior quantidade de fertilizantes, menor foi a representatividade da calagem nos custos totais. No ANO 4, com uso de suplementação de $0,7 \%$ do PV, a calagem representou no sistema DFAS apenas 3,88\% dos custos totais. Mesmo em sistemas de produção com menor utilização de insumos, nos quais cada fração tem maior representatividade, os custos com a correção do solo não ultrapassaram $10 \%$ dos custos totais.

A aplicação de calcário reduz a acidez do solo e eleva a disponibilidade de macro e micronutrientes para as plantas. Além disso, melhora as condições estruturais do solo ao longo dos anos. Siqueira (1989), considerando a situação da fertilidade do solo no Estado do Rio Grande do Sul e seus reflexos no desenvolvimento das principais culturas, relatou que as limitações devidas à acidez do solo situam-se em torno de $15 \%$. Este estudo não inclui o efeito da interação entre a calagem e a adubação fosfatada, e

Tabela 2 - Custos/ha referentes à calagem e sistema de plantio em percentagem do custo total e $\mathrm{kg}$ de peso vivo (kg PV) para sistemas de recria de fêmeas de corte. Santa Maria, período de 1998 a 2001

Table 2 - Costs/ha for liming and sowing system, in percentage of total costs and $\mathrm{kg}$ of live weight ( $\mathrm{kg} L W$ ) for rearing of beef heifers systems. Santa Maria, period from 1998 to 2001

\begin{tabular}{|c|c|c|c|c|c|}
\hline \multirow[t]{2}{*}{$\begin{array}{l}\text { Ano } \\
\text { Year }\end{array}$} & \multirow[t]{2}{*}{$\begin{array}{l}\text { Sistema } \\
\text { System }\end{array}$} & \multicolumn{2}{|c|}{$\begin{array}{l}\text { Calagem } \\
\text { Liming }\end{array}$} & \multicolumn{2}{|c|}{$\begin{array}{l}\text { Sistema de plantio } \\
\text { Sowing system }\end{array}$} \\
\hline & & $\%$ & $\begin{array}{l}\mathrm{kg} \mathrm{PV} \\
\mathrm{kg} L W\end{array}$ & $\%$ & $\begin{array}{l}\mathrm{kgPV} \\
\mathrm{kg} L W\end{array}$ \\
\hline \multirow{6}{*}{1} & & & & \multicolumn{2}{|c|}{$\begin{array}{c}\text { Convencional } \\
\text { Conventional }\end{array}$} \\
\hline & STP & 3,79 & 20,69 & 5,32 & 29,09 \\
\hline & SAS & 4,71 & 20,69 & 6,63 & 29,09 \\
\hline & SS & 7,77 & 20,69 & 10,92 & 29,09 \\
\hline & & & & \multicolumn{2}{|c|}{$\begin{array}{l}\text { Plantio direto } \\
\text { No tillage }\end{array}$} \\
\hline & Т 0 & 7,50 & 20,69 & 16,72 & 46,15 \\
\hline \multirow[t]{3}{*}{2} & $\mathrm{~T} 0,7$ & 4,88 & 20,69 & 10,88 & 46,15 \\
\hline & $\mathrm{T} 1,4$ & 3,29 & 20,69 & 7,34 & 46,15 \\
\hline & AAS & 3,26 & 20,69 & 7,27 & 46,16 \\
\hline \multirow[t]{4}{*}{3} & AAN & 4,65 & 20,69 & 10,37 & 46,16 \\
\hline & AAL & 8,87 & 33,10 & 12,37 & 46,16 \\
\hline & DFB & 5,98 & 20,69 & 11,56 & 40,02 \\
\hline & DFA & 6,00 & 20,69 & 11,60 & 40,02 \\
\hline \multirow[t]{2}{*}{4} & DFBS & 3,88 & 20,69 & 7,50 & 40,02 \\
\hline & DFAS & 4,13 & 20,69 & 7,99 & 40,02 \\
\hline
\end{tabular}

1 - Rocha et al. (2003a) = STP - suplementação todo período; SAS - suplementação até setembro; SS - sem suplementação.

2 - Frizzo et al. (2003) = T0 - sem suplementação; T0,7 - suplementação 0,7\% PV; T1,4 - suplementação 1,4\% do PV.

3 - Rocha et al. $(2003 \mathrm{~b})$ = AAS - aveia + azevém + suplementação; AAN - aveia + azevém + nitrogênio; AAL - aveia + azevém + trevo.

4 - Rocha et al. (2003) = DFB - disponibilidade de forragem baixa; DFA - disponibilidade de forragem alta; DFBS - disponibilidade de forragem baixa + suplementação; DFAS - disponibilidade de forragem alta + suplementação.

1 - Rocha et al.(2003a) = STP - supplementation during all pasture cycle; SAS - supplementation until September; SS - no supplementation.

2 - Frizzo et al. (2003) = TO - no supplementation; T0.7- supplementation 0.7\% LW; T1;4- supplementation $1.4 \%$ LW.

3 - Rocha et al. $(2003 b)=A A S$ - oat + ryegrass + supplementation; AAN - oat + ryegrass + nitrogen; $A A L$ - oat + ryegrass + clover.

4 - Rocha et al. (2003) = DFB - low forage availability; DFA - high forage availability; DFBS - low forage availability and supplementation; DFAS - high forage availability and supplementation.

R. Bras. Zootec., v.32, n.4, p.966-976, 2003 
o autor supra citado acredita, em função disso, que as estimativas ultrapassem este valor apresentado.

A implantação da pastagem pelo sistema convencional, no ANO 1, teve custo de 29,09 kg/ha de PV. O sistema de plantio direto, com dessecação prévia da área, por outro lado, representou um custo de $46,15 \mathrm{~kg} /$ ha de $\mathrm{PV}$, quando foram utilizados $3 \mathrm{~L} / \mathrm{ha}$ de dessecante (ANOS 2 e 3). Com a dosagem de dessecante de $2 \mathrm{~L} / \mathrm{ha}$ (ANO 4) o custo foi reduzido para $40,02 \mathrm{~kg} / \mathrm{ha}$ de PV.

Em áreas cultivadas com lavouras de verão, é possível diminuir a dose/ha de herbicida ou mesmo implantar a pastagem de inverno sem dessecação prévia, reduzindo o custo do plantio direto. Menor dose do dessecante pode tornar este sistema economicamente tão eficiente quanto o convencional. Confirma-se, então, a afirmação que integrar a pastagem de inverno com lavouras de verão é uma importante estratégia de redução de custos (Pötter et al., 2000). Os benefícios da integração lavoura-pecuária podem ser resumidos em: aumento da rentabilidade, diminuição da dependência dos produtores dos cultivos singulares, redução dos riscos de inviabilização do negócio agrícola e produção de leite e carne de forma altamente competitiva em relação a custo e qualidade (Moraes et al., 1999).

O sistema de plantio direto apresenta, ainda, grandes vantagens em relação à estrutura do solo e ao controle de invasoras ao longo dos anos, mesmo com um custo/ha mais elevado. O pouco revolvimento do solo diminui as perdas por lixiviação e exposição ao sol e estimula, em menor intensidade, o banco de sementes daninhas já existente. Na área experimental, nos ANOS 2, 3 e 4, foi marcante a diminuição de invasoras, principalmente nabo (Raphanus sativus) e língua de vaca (Echium plantagineum), após utilização do plantio direto.

$\mathrm{Na}$ Tabela 3, encontram-se os custos/ha de sementes, adubação e adubação nitrogenada em cobertura, em porcentagem dos custos totais e $\mathrm{kg}$ de PV. A aveia e o azevém são as duas espécies de inverno mais cultivadas para pastejo no Rio Grande do Sul. Consorciadas, suas sementes apresentaram custos entre 32,07 e $35,79 \mathrm{~kg} / \mathrm{ha}$ de PV, representando, em média, $8 \%$ dos custos totais. $\mathrm{O}$ azevém apresenta facilidade de ressemeadura natural, resistência a

Tabela 3 - Custos/ha referentes a sementes, adubação e adubação nitrogenada, em percentagem do custo total e kg de peso vivo (kg PV) para sistemas de recria de fêmeas de corte. Santa Maria, período de 1998 a 2001

Table 3 - Costs/ha for seeds, fertilization and nitrogen fertilization in percentage of total costs and $\mathrm{kg}$ of live weight (kg LW) for rearing of beef heifers systems. Santa Maria, period from 1998 to 2001

\begin{tabular}{|c|c|c|c|c|c|c|c|}
\hline \multirow[t]{2}{*}{$\begin{array}{l}\text { Ano } \\
\text { Year }\end{array}$} & \multirow[t]{2}{*}{$\begin{array}{l}\text { Sistema } \\
\text { System }\end{array}$} & \multicolumn{2}{|c|}{$\begin{array}{l}\text { Sementes } \\
\text { Seeds }\end{array}$} & \multicolumn{2}{|c|}{$\begin{array}{l}\text { Adubação } \\
\text { Fertilization }\end{array}$} & \multicolumn{2}{|c|}{$\begin{array}{c}\text { Nitrogênio } \\
\text { Nitrogen }\end{array}$} \\
\hline & & $\%$ & $\begin{array}{l}\mathrm{kg} \mathrm{PV} \\
k g \quad L W\end{array}$ & $\%$ & $\begin{array}{ll}\mathrm{kg} & \mathrm{PV} \\
k g & L W\end{array}$ & $\%$ & $\begin{array}{l}\mathrm{kg} \mathrm{PV} \\
\mathrm{kg} \quad L W\end{array}$ \\
\hline \multirow{4}{*}{1} & STP & 5,87 & 32,07 & 11,87 & 64,83 & 16,39 & 89,50 \\
\hline & SAS & 7,31 & 32,07 & 14,77 & 64,83 & 20,40 & 89,50 \\
\hline & SS & 12,04 & 32,07 & 24,34 & 64,83 & 33,60 & 89,50 \\
\hline & Т 0 & 12,75 & 35,17 & 23,49 & 64,83 & 26,40 & 72,86 \\
\hline \multirow[t]{3}{*}{2} & Т 0,7 & 8,30 & 35,17 & 15,29 & 64,83 & 17,18 & 72,86 \\
\hline & $\mathrm{T} 1,4$ & 5,60 & 35,17 & 10,32 & 64,83 & 11,60 & 72,86 \\
\hline & AAS & 5,64 & 35,79 & 15,33 & 97,24 & 18,52 & 117,51 \\
\hline \multirow[t]{4}{*}{3} & AAN & 8,04 & 35,79 & 21,85 & 97,24 & 50,16 & 223,25 \\
\hline & AAL & 16,06 & 59,93 & 26,06 & 97,24 & 30,87 & 115,15 \\
\hline & DFB & 9,57 & 33,10 & 28,10 & 97,24 & 38,37 & 132,78 \\
\hline & DFA & 9,59 & 33,10 & 28,18 & 97,24 & 38,48 & 132,78 \\
\hline \multirow[t]{2}{*}{4} & DFBS & 6,20 & 33,10 & 18,22 & 97,24 & 24,88 & 132,78 \\
\hline & DFAS & 6,61 & 33,10 & 19,43 & 97,24 & 26,52 & 132,78 \\
\hline
\end{tabular}

1 - Rocha et al. (2003a) = STP - suplementação todo período; SAS - suplementação até setembro; SS - sem suplementação.

2 - Frizzo et al. (2003) = T0 - sem suplementação; T0,7 - suplementação 0,7\% PV; T1,4 - suplementação 1,4\% do PV.

3 - Rocha et al. $(2003 \mathrm{~b})$ = AAS - aveia + azevém + suplementação; AAN - aveia + azevém + nitrogênio; AAL - aveia + azevém + trevo.

4 - Rocha et al. (2003) = DFB - disponibilidade de forragem baixa; DFA - disponibilidade de forragem alta; DFBS - disponibilidade de forragem baixa + suplementação; DFAS - disponibilidade de forragem alta + suplementação.

1 - Rocha et al. (2003a) = STP - supplementation during all pasture cycle; SAS - supplementation until September; SS - no supplementation.

2 - Frizzo et al. (2003) = TO - no supplementation; T0.7- supplementation $0.7 \%$ LW; T1; - supplementation $1.4 \%$ LW.

3 - Rocha et al. $(2003 \mathrm{~b})=A A S$ - oat + ryegrass + supplementation; $A A N$ - oat + ryegrass + nitrogen; $A A L-$ oat + ryegrass + clover.

4 - Rocha et al. (2003) = DFB - low forage availability; DFA - high forage availability; DFBS - low forage availability and supplementation; DFAS - high forage availability and supplementation.

R. Bras. Zootec., v.32, n.4, p.966-976, 2003 
doenças, bom potencial de produção de sementes e versatilidade de uso em misturas (Floss, 1988). Quando semeado na quantidade de $43 \mathrm{~kg} / \mathrm{ha}$ no ANO 3, (Tabela 1) acresceu apenas $1,5 \mathrm{~kg} / \mathrm{ha}$ de PV, em relação à utilização de $30 \mathrm{~kg} /$ ha de semente no ANO 1 . $\mathrm{O}$ uso de maior densidade de sementes de azevém tem sido usual nos sistemas de produção pecuário, visando garantir uma boa implantação da pastagem.

A utilização do trevo vesiculoso representou acréscimo nos custos com sementes de $24 \mathrm{~kg} / \mathrm{ha}$ de $\mathrm{PV}$, em relação à mistura de aveia + azevém, correspondendo a $5 \%$ do custo total/ha do sistema AAL, no ANO 3. As leguminosas temperadas são utilizadas na agricultura moderna por suas características de contribuir na fixação do nitrogênio atmosférico para as pastagens e culturas subseqüentes, e por apresentarem alto valor nutritivo e consumo voluntário quando comparadas com gramíneas temperadas em estádios similares de desenvolvimento. A elevação nos custos, quando existe a utilização de uma leguminosa na mistura, está relacionada com maior exigência em fertilidade do solo, existindo, em muitos casos, a necessidade de uso de uma dose mais elevada de fertilizante fosfatado e correção da acidez. O trevo vesiculoso não tolera solos mal drenados e é muito sensível a baixos níveis de $\mathrm{P}$ e $\mathrm{K}$, especialmente do primeiro (Quadros \& Maraschin, 1987).

$\mathrm{O}$ índice de fertilidade da área experimental, em 1996, apresentou $\mathrm{pH}$ em torno de 4,7, teor de $\mathrm{K}$ suficiente e P alto. Segundo a Comissão de Fertilidade do Solo (Rolas, 1999), a faixa suficiente corresponde ao nível crítico dos nutrientes. Abaixo dos valores mencionados, a probabilidade de comprometimento do desenvolvimento das culturas aumenta em função da disponibilidade do nutriente especificado. O teor alto para P e K no solo corresponde ao nível para máxima eficiência técnica. Amostras colhidas em 2001, cinco anos depois da amostragem referida acima, mostraram a elevação do $\mathrm{pH}$ para 5,5. Este valor, no entanto, foi inferior ao recomendado para a máxima eficiência técnica de gramíneas e leguminosas de estação fria (Rolas, 1999). O teor de P, por outro lado, manteve-se alto e o nível de $\mathrm{K}$ passou de suficiente para alto.

No decorrer dos anos, a toxidez por alumínio foi controlada chegando a $0 \mathrm{Cmol} / \mathrm{L}$. A concentração de alumínio trocável ou solúvelé, provavelmente, o mais importante limitador do desenvolvimento ou produção das plantas cultivadas em solos ácidos e também é usado como indicador da necessidade de correção da acidez (Kaminski, 1989). Houve, ainda, aumento no teor de $\mathrm{MO}$ de $0,60 \%$ nos quatro anos entre as amostragens.

A adubação utilizada em 1998 e 1999 foi de $200 \mathrm{~kg} /$ ha da fórmula 5-20-20, por ocasião do plantio. Nestes anos, este item representou um custo de 64,83 $\mathrm{kg} / \mathrm{ha}$ de PV para elevar as condições do solo à máxima eficiência técnica em $\mathrm{P}$ e K. O aumento na quantidade de adubo para $300 \mathrm{~kg} / \mathrm{ha}$, em 2000 e 2001, foi de grande relevância na avaliação econômica. Nestes anos, foram gastos 97,24 kg/ha de PV em adubação de manutenção, chegando a representar $28 \%$ dos custos/ha do sistema DFB, no ANO 4. Nesta quantidade, a adubação foi fator determinante para elevação dos custos totais em relação a sistemas igualmente tecnificados, avaliados em outros anos.

$\mathrm{O}$ uso de nitrogênio em cobertura teve forte participação nos custos/ha da maioria dos sistemas. Sua aplicação, porém, é de extrema importância. Em pastagem de aveia + azevém, Restle et al. (1993) observaram resposta linear em produção animal com até $300 \mathrm{~kg} / \mathrm{ha}$ de $\mathrm{N}$, na forma de uréia. A partir desta dose, não há aumento na produção de forragem e sua aplicação passa a ser biologicamente inviável (Soares \& Restle, 2002).

No sistema AAN, ANO 3, a adubação nitrogenada de $300 \mathrm{~kg} / \mathrm{ha}$ de $\mathrm{N}$ representou $50 \%$ dos custos totais. Zimmer \& Euclides Filho (1997) salientam que a adubação nitrogenada, além de ter efeito residual curto, apresenta pouco efeito cumulativo ao longo do tempo. Estes fatores, aliados ao alto custo, impedem que sua utilização, em doses elevadas, seja generalizada.

$\mathrm{Na}$ Tabela 4, estão quantificados os custos/ha da suplementação e dos fertilizantes (adubação + adubação de cobertura) em percentual e kg de PV. A economicidade de sistemas que utilizam suplementação é dependente do custo do suplemento. A escolha de um ou mais alimentos abundantes na região resulta num menor custo de aquisição e de transporte e, também, num acompanhamento dinâmico da relação preços de produtos/insumos (Pötter et al., 2000). Quando o suplemento fornecido foi sorgo moído, na proporção de $0,7 \%$ do $\mathrm{PV}$, no ANO 4 , no sistema DFBS, seu custo correspondeu a $187,38 \mathrm{~kg} / \mathrm{ha}$ de PV. Já no ANO 2, quando o suplemento foi polpa cítrica + farelo de arroz, também correspondendo a $0,7 \%$ do PV (T 0,7), o custo da suplementação foi $143,33 \mathrm{~kg} / \mathrm{ha}$ de $\mathrm{PV}$, correspondendo a uma variação de $30 \%$ no custo relativo, dependendo do tipo de suplemento. As produções de $\mathrm{PV} / \mathrm{ha}$ variaram em $6 \%$, sendo de 
604 e $563 \mathrm{~kg} / \mathrm{ha}$ de PV, nos anos 4 e 2, respectivamente (Tabela 5).

A suplementação teve grande participação na composição dos custos totais/ha. No ANO 2, quando usada na quantidade de $1,4 \%$ do PV, chegou a representar um custo de $338,42 \mathrm{~kg}$ de $\mathrm{PV}$, valor provavelmente muito alto para proporcionar um incremento similar adicional de PV/ha (Tabela 4).

Para potencializar economicamente o incremento em produção animal proporcionado pela suplementação dos animais, em relação ao uso de apenas pastagem de aveia + azevém, é necessário trabalhar com suplementos de baixo custo. A grande vantagem em investir na suplementação em relação ao uso exclusivo da pastagem, entretanto, está no risco quase nulo ligado ao fornecimento do suplemento, pois a quantidade oferecida não depende de condições climáticas. Rocha et al. (2001a) apresentam como uma das maiores vantagens da suplementação a aceleração no ganho de peso dos animais antecipando a liberação da área para outras categorias ou para implantação de culturas de verão. Rearte (1999) salienta que a suplementação energética com concentrado é a principal ferramenta para assegurar o desempenho esperado para os animais, portanto, não pode ser analisada somente em relação ao custo/ benefício em determinado momento, e sim pelo que significa em todo o plantel empresarial, considerando o ciclo completo.

Na Figura 1, encontram-se o custo/ha (kg de PV), o ganho de PV/ha e a margem bruta/ha (kg de PV), quando foi simulada uma variação no preço do $\mathrm{kg}$ do suplemento. Para simulação foi utilizado o tratamento com nível de suplementação de $0,7 \%$ do PV do ANO 2 $(\mathrm{T} 0,7)$ por ter apresentado a melhor resposta animal à suplementação. O sistema utilizado para comparação foi o sem suplemento, no mesmo ano.

A suplementação permitiu margem bruta/ha superior ao não suplementado quando o valor do suplemento foi de $0,05 \mathrm{~kg}$ de PV (50 g de PV) o kg. Ao preço de $0,16 \mathrm{~kg}$ de PV (160 g de PV), o ganho de peso vivo/ha cobriria apenas os custos de produção do sistema avaliado.

A eficiência técnica dos sistemas de produção foi avaliada a partir dos resultados biológicos. Na Tabela 5, encontram-se os valores referentes a ganho médio diário (GMD), carga animal (CA) e ganho de peso vivo por hectare (GPV) para todos os sistemas analisados. O desempenho econômico na recria de fêmeas depende do sistema de produção no qual elas estão inseridas. A partir do planejamento do ganho de peso necessário para as novilhas atingirem condições de acasalamento no tempo previsto, busca-se o sistema alimentar mais adequado.

Quando, em fêmeas de corte, a idade pretendida ao primeiro acasalamento é de 14 meses, faz-se necessário um ganho de peso no primeiro inverno pós-desmama em torno de 0,7 a $1 \mathrm{~kg} / \mathrm{dia}$, dependendo da raça e do peso destas fêmeas na desmama. Nos sistemas avaliados, com uso de suplementação, foram observadas médias de GMD de 0,700;0,873; 0,744 e $0,794 \mathrm{~kg}$, do ANO 1 ao ANO 4, respectivamente. No ANO 4, houve incremento de $43 \%$ no ganho individual dos animais recebendo suplemento ao nível de $0,7 \%$ do PV (DFBS), comparado com o GMD proporcionado pela disponibilidade de forra-

Tabela 4 - Custos/ha referentes à suplementação e fertilizantes em percentagem do custo total e $\mathrm{kg}$ de peso vivo ( $\mathrm{kg} \mathrm{PV}$ ) para sistemas de recria de fêmeas de corte. Santa Maria, período de 1998 a 2001

Table 4 - Costs/ha for supplementation and fertilizers in percentage of total costs and $\mathrm{kg}$ of live weight $(\mathrm{kg}$ $L W)$ in rearing of beef heifers systems. Santa Maria, period from 1998 to 2001

\begin{tabular}{|c|c|c|c|c|c|}
\hline \multirow[t]{2}{*}{$\begin{array}{l}\text { Ano } \\
\text { Year }\end{array}$} & \multirow[t]{2}{*}{$\begin{array}{l}\text { Sistema } \\
\text { System }\end{array}$} & \multicolumn{2}{|c|}{$\begin{array}{l}\text { Suplementação } \\
\text { Supplementation }\end{array}$} & \multicolumn{2}{|c|}{$\begin{array}{c}\text { Fertilizantes } \\
\text { Fertilizers }\end{array}$} \\
\hline & & $\%$ & $\begin{array}{l}\mathrm{kgPV} \\
k g \quad L W\end{array}$ & $\%$ & $\begin{array}{l}\mathrm{kgPV} \\
\mathrm{kg} \quad L W\end{array}$ \\
\hline \multirow[t]{2}{*}{1} & STP & 49,99 & 272,94 & 28,26 & 154,33 \\
\hline & SAS & 38,12 & 167,28 & 35,17 & 154,33 \\
\hline \multirow[t]{2}{*}{2} & $\mathrm{~T}-0,7$ & 33,80 & 143,33 & 32,47 & 137,69 \\
\hline & $\mathrm{T}-1,4$ & 53,86 & 338,42 & 21,92 & 137,69 \\
\hline 3 & AAS & 46,38 & 294,27 & 33,84 & 214,75 \\
\hline \multirow[t]{2}{*}{4} & DFBS & 35,10 & 187,38 & 43,09 & 230,02 \\
\hline & DFAS & 30,99 & 155,13 & 45,95 & 230,02 \\
\hline
\end{tabular}

1 - Rocha et al. (2003a) = STP - suplementação todo período; SAS - suplementação até setembro; SS - sem suplementação.

2 - Frizzo et al. $(2003)=$ T0 - sem suplementação; T0,7 suplementação $0,7 \%$ PV; T1,4 - suplementação 1,4\% do PV.

3 - Rocha et al. $(2003 \mathrm{~b})$ = AAS - aveia + azevém + suplementação; AAN - aveia + azevém + nitrogênio; AAL - aveia + azevém + trevo.

4 - Rocha et al. (2003) = DFB - disponibilidade de forragem baixa; DFA - disponibilidade de forragem alta; DFBS - disponibilidade de forragem baixa + suplementação; DFAS - disponibilidade de forragem alta + suplementação.

1 - Rocha et al. (2003a) = STP - supplementation during all pasture cycle; SAS - supplementation until September; SS - no supplementation.

2 - Frizzo et al. (2003) = TO - no supplementation; TO.7- supplementation $0.7 \%$ LW; $T 1 ; 4$ - supplementation $1.4 \%$ LW.

3 - Rocha et al. $(2003 \mathrm{~b})=A A S-$ oat + ryegrass + supplementation; $A A N$ - oat + ryegrass + nitrogen; $A A L$ - oat + ryegrass + clover.

4 - Rocha et al. (2003) = DFB - low forage availability; DFA - high forage availability; DFBS - low forage availability and supplementation; DFAS - high forage availability and supplementation. 
gem baixa, sem suplemento. O maior ganho de peso dos animais, quando suplementados, permitiria, por exemplo, utilização de suplemento somente para fêmeas com menor desenvolvimento corporal aos sete

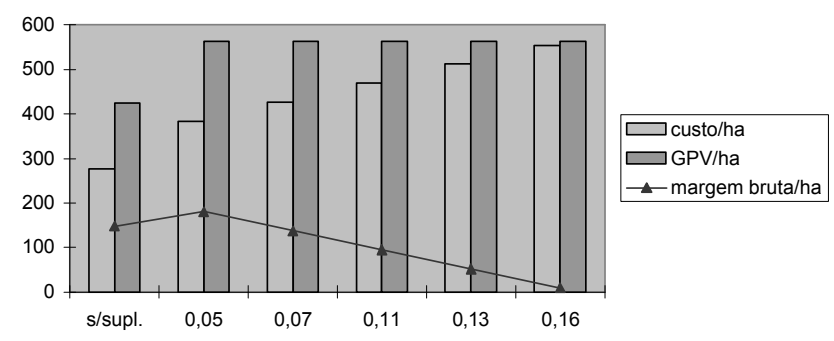

Figura 1 - Efeito da variação no preço do kg de suplemento (kg de PV) sobre a margem bruta (kg/ha de PV).

Figure 1 - Effect of supplement $\mathrm{kg}$ price variation $(\mathrm{kg}$ of $L W)$ on gross margin ( $\mathrm{Kg} / \mathrm{ha}$ of $\mathrm{LW}$ ). meses, com objetivo de obter maior uniformidade das novilhas ao final da utilização da pastagem de inverno. O nível de suplementação energética necessária para recuperar o desenvolvimento de novilhas abaixo do peso crítico, após o desmame, está entre 0,8 e 1\% do PV (MSD AGVET, 1992).

A maioria das novilhas reduz a idade à puberdade e idade ao primeiro serviço quando são atendidas as suas exigências nutricionais no primeiro e/ou segundo período hibernal (Lobato, 1997). Sistemas utilizando apenas pastagem cultivada oportunizaram ganhos de peso, no primeiro inverno pós-desmama, acima das exigências nutricionais das novilhas para seu acasalamento aos 24 meses de idade. Este sistema de acasalamento permite ganho de peso compensatório durante as fases de recria, o que não ocorre no "sistema um ano". A suplementação energética dos animais, em pastagem cultivada de inverno, neste caso, passa a ser desnecessária.

A carga animal foi superior nos tratamentos suplementados nos quatro anos. No ANO 2, a

Tabela 5 - Ganho médio diário (GMD), carga animal (CA) e ganho de peso vivo (GPV) para sistemas de produção para recria de fêmeas de corte. Santa Maria, período de 1998 a 2001

Table 5 - Daily live weight gain (DLWG), stocking rate ( $\mathrm{kg}$ of LW/ha) and live weight gain (LWG/ha) in rearing of beef heifers systems. Santa Maria, period from 1998 to 2001

\begin{tabular}{|c|c|c|c|c|}
\hline $\begin{array}{l}\text { Ano } \\
\text { Year }\end{array}$ & $\begin{array}{l}\text { Sistema } \\
\text { System }\end{array}$ & $\begin{array}{c}\text { GMD } \\
D L W G \\
\mathrm{~kg} / \mathrm{dia} \mathrm{PV} \\
\mathrm{kg} / \text { day } L W\end{array}$ & $\begin{array}{c}\text { Carga animal } \\
\text { Stocking rate } \\
\mathrm{kg} / \mathrm{ha} \mathrm{PV} \\
\mathrm{kg} / \mathrm{ha} L W\end{array}$ & $\begin{array}{c}\text { GPV } \\
L W G / h a \\
\mathrm{~kg} / \mathrm{ha} \mathrm{PV} \\
\mathrm{kg} / \mathrm{ha} L W\end{array}$ \\
\hline & STP & $0,690^{\mathrm{a}}$ & $1120^{\mathrm{a}}$ & $627^{a}$ \\
\hline \multirow[t]{3}{*}{1} & SAS & $0,710^{\mathrm{a}}$ & $985^{\mathrm{a}}$ & $540^{b}$ \\
\hline & $\mathrm{SS}$ & $0,580^{b}$ & $708^{b}$ & $359^{c}$ \\
\hline & T- 0 & $0,716^{b}$ & $987^{c}$ & $424^{b}$ \\
\hline \multirow[t]{3}{*}{2} & T- 0,7 & $0,901^{\mathrm{a}}$ & $1244^{b}$ & $563^{a}$ \\
\hline & $\mathrm{T}-1,4$ & $0,844^{\mathrm{ab}}$ & $1708^{a}$ & $671^{a}$ \\
\hline & AAS & 0,744 & $1360^{a}$ & $603^{a}$ \\
\hline \multirow[t]{3}{*}{3} & AAN & 0,728 & $1163^{b}$ & $495^{b}$ \\
\hline & AAL & 0,986 & $1049^{b}$ & $485^{b}$ \\
\hline & DFB & $0,545^{b}$ & $1003^{b}$ & $352^{b}$ \\
\hline \multirow[t]{3}{*}{4} & DFA & $0,610^{b}$ & $862^{b}$ & $324^{b}$ \\
\hline & DFBS & $0,779^{a}$ & $1222^{a}$ & $604^{\mathrm{a}}$ \\
\hline & DFAS & $0,809^{\mathrm{a}}$ & $969^{b}$ & $449^{a}$ \\
\hline
\end{tabular}

Médias na coluna seguidas por letras diferentes $(a, b, c)$, diferem estatisticamente $(P<0,05)$.

Means with different letters $(a, b, c)$ in same column are different statistically $(P<.05)$.

1 - Rocha et al. (2003a) = STP - suplementação todo período; SAS - suplementação até setembro; SS - sem suplementação.

2 - Frizzo et al. (2003) = T0 - sem suplementação; T0,7 - suplementação 0,7\% PV; T1,4 - suplementação 1,4\% do PV.

3 - Rocha et al. (2003b) = AAS - aveia + azevém + suplementação; AAN - aveia + azevém + nitrogênio; AAL - aveia + azevém + trevo.

4 - Rocha et al. (2003) = DFB - disponibilidade de forragem baixa; DFA - disponibilidade de forragem alta; DFBS - disponibilidade de forragem baixa + suplementação; DFAS - disponibilidade de forragem alta + suplementação.

1 - Rocha et al.(2003a) = STP - supplementation during all pasture cycle; SAS - supplementation until September; SS - no supplementation.

2 - Frizzo et al. (2003) = TO - no supplementation; T0.7- supplementation 0.7\% LW; T1;4 - supplementation $1.4 \%$ LW.

3 - Rocha et al. $(2003 b)=A A S-$ oat + ryegrass + supplementation; AAN - oat + ryegrass + nitrogen; AAL - oat + ryegrass + clover.

4 - Rocha et al. (2003) = DFB - low forage availability; DFA - high forage availability; DFBS - low forage availability and supplementation; DFAS - high forage availability and supplementation.

R. Bras. Zootec., v.32, n.4, p.966-976, 2003 
suplementação dos animais com 1,4\% do PV proporcionou carga animal $73 \%$ superior ao sistema sem suplemento. Para mesma oferta de forragem (ANOS 1,2 e 3), $10 \%$ do PV, e mesmo com ofertas diferentes proporcionadas pelas diferentes massas de forragem (ANO 4), maiores suportes em carga animal e um bom desempenho individual garantiram, em sistemas com suplementação energética, ganho de PV/ha superior aos sistemas sem suplementação avaliados contemporaneamente. Quando ocorre aumento da carga animal em pastagens temperadas, sem manter uma oferta de forragem adequada, a forragem disponível é reduzida e, conseqüentemente, o desempenho por animal diminui (Phillips, 1988).

$\mathrm{Na}$ avaliação da margem bruta, mantendo-se o preço de venda do produto constante, a melhor resposta econômica não foi correspondente ao melhor desempenho biológico. Na Tabela 6, estão quantificados custos variáveis, ganho de PV e margem bruta para os quatro sistemas de produção avaliados. No ANO 1, a relação entre produção animal e custo de produção foi bastante próxima nos sistemas de alimentação. Mesmo assim, com suplementação dos animais até setembro (SAS), foi observada margem bruta 11 e $23 \%$ superior, respectivamente, ao uso exclusivo da pastagem (SS) e suplementação dos animais em todo período (STP). Nestas condições, optar pelo sistema que apresenta a melhor relação entre desempenho individual e carga animal é uma boa alternativa.

O bom desenvolvimento de maior número de fêmeas em uma mesma área de pastagem representa um maior número de fêmeas aptas à reprodução em menor tempo. Conforme Rovira (1974), a redução de categorias em desenvolvimento dentro de rebanhos com sistemas de produção mais intensivos determina aumento na eficiência de estoque.

Quando níveis de suplementação foram testados, no ANO 2, foi observada grande influência do desempenho individual dos animais sobre a resposta econômica. Ao aumentar o nível de suplemento de 0,7 para $1,4 \%$ do $\mathrm{PV}$, não foi verificada diferença no ganho médio diário dos animais (Tabela 5) e a margem bruta foi reduzida de 137 para $39 \mathrm{~kg} / \mathrm{ha}$ de $\mathrm{PV}$. O maior ou menor potencial para elevar a rentabilidade de um

Tabela 6 - Custos variáveis, ganho de peso vivo e margem bruta em sistemas de produção para recria de fêmeas de corte. Santa Maria, período de 1998 a 2001

Table 6 - Variable costs, live weight gain and gross margin in rearing of beef heifers systems. Santa Maria, period from 1998 to 2001

\begin{tabular}{|c|c|c|c|c|}
\hline \multirow[t]{3}{*}{$\begin{array}{l}\text { Ano } \\
\text { Year }\end{array}$} & \multirow[t]{3}{*}{$\begin{array}{l}\text { Sistema } \\
\text { System }\end{array}$} & $\begin{array}{l}\text { Custos variáveis } \\
\text { Variable costs }\end{array}$ & \multirow{3}{*}{$\begin{array}{c}\text { Ganho de peso vivo } \\
\text { Live weight gain } \\
\mathrm{kg} / \mathrm{haPV} \\
\mathrm{kg} / \mathrm{ha} L W\end{array}$} & \multirow[t]{3}{*}{$\begin{array}{l}\text { Margem bruta } \\
\text { Gross margin }\end{array}$} \\
\hline & & & & \\
\hline & & & & \\
\hline & STP & 554 & 627 & 83 \\
\hline \multirow[t]{3}{*}{1} & SAS & 438 & 540 & 102 \\
\hline & SS & 267 & 359 & 92 \\
\hline & T- 0 & 276 & 424 & 148 \\
\hline \multirow[t]{3}{*}{2} & $\mathrm{~T}-0,7$ & 426 & 563 & 137 \\
\hline & $\mathrm{T}-1,4$ & 632 & 671 & 39 \\
\hline & AAS & 632 & 603 & -29 \\
\hline \multirow[t]{3}{*}{3} & AAN & 445 & 495 & 50 \\
\hline & AAL & 373 & 485 & 112 \\
\hline & DFB & 346 & 352 & 6 \\
\hline \multirow[t]{3}{*}{4} & DFA & 345 & 324 & -21 \\
\hline & DFBS & 532 & 604 & 72 \\
\hline & DFAS & 499 & 449 & -50 \\
\hline
\end{tabular}

1 - Rocha et al. (2003a) = STP - suplementação todo período; SAS - suplementação até setembro; SS - sem suplementação.

2 - Frizzo et al. (2003) = T0 - sem suplementação; T0,7 - suplementação 0,7\% PV; T1,4 - suplementação 1,4\% do PV.

3 - Rocha et al. (2003b) = AAS - aveia + azevém + suplementação; AAN - aveia + azevém + nitrogênio; AAL - aveia + azevém + trevo.

4 - Rocha et al. (2003) = DFB - disponibilidade de forragem baixa; DFA - disponibilidade de forragem alta; DFBS - disponibilidade de forragem baixa + suplementação; DFAS - disponibilidade de forragem alta + suplementação.

1 - Rocha et al. (2003a) = STP - supplementation during all pasture cycle; SAS - supplementation until September; SS - no supplementation.

2 - Frizzo et al. (2003) = TO - no supplementation; T0.7- supplementation 0.7\% LW; T1;4 - supplementation $1.4 \%$ LW.

3 - Rocha et al. $(2003 b)=A A S-$ oat + ryegrass + supplementation; AAN-oat + ryegrass + nitrogen; AAL-oat + ryegrass + clover.

4 - Rocha et al. (2003) = DFB - low forage availability; DFA - high forage availability; DFBS - low forage availability and supplementation; DFAS - high forage availability and supplementation.

R. Bras. Zootec., v.32, n.4, p.966-976, 2003 
rebanho depende, certamente, do custo da alimentação hibernal adicional para manter a taxa adequada de crescimento das novilhas, que poderá exceder qualquer acréscimo na renda advinda da produção subseqüente de bezerros (Rocha, 1997).

É importante assegurar que o valor do custo do sistema alimentar seja inferior ao potencial de produção animal em pastagens de inverno, cujos maiores valores foram de 671 e $627 \mathrm{~kg} / \mathrm{ha}$ de PV, nos ANOS 2 e 1, respectivamente. No ANO 3, bons ganhos de $\mathrm{PV}$, proporcionados tanto pela suplementação quanto pela alta dose de nitrogênio, não resultaram em resposta econômica satisfatória. Entre os sistemas avaliados neste ano, a utilização da mistura de aveia + azevém + trevo apresentou custo de produção bem inferior aos demais sistemas e possibilitou margem bruta de $112 \mathrm{~kg} / \mathrm{ha}$ de PV.

Resultados biológicos observados no ANO 4 para GPV não foram satisfatórios, principalmente nos tratamentos sem suplementação energética aos animais (DFB e DFA). Condições climáticas desfavoráveis ao crescimento das pastagens e seu elevado custo de implantação determinaram, em média, margem bruta inferior à dos demais anos. A prática de suplementação dos animais associada à disponibilidade de forragem baixa possibilitou margem bruta de $72 \mathrm{~kg} / \mathrm{ha}$ de PV (DFBS). Animais exclusivamente em pastejo sob disponibilidade de forragem baixa, porém, apresentaram GPV suficiente apenas para cobrir os custos de produção. Sistemas com maior dependência da produção de forragem (DFA e DFAS) e, portanto, com carga animal reduzida, representaram prejuízo de 21 e $50 \mathrm{~kg} / \mathrm{ha}$ de PV.

\section{Conclusões}

Na utilização de pastagens de aveia e azevém para a recria de fêmeas de corte, o preço pago pelo $\mathrm{kg}$ de suplemento deve se situar na faixa de 0,05 a $0,07 \mathrm{~kg}$ de peso vivo para tornar seu uso economicamente viável em relação ao uso exclusivo da pastagem.

A suplementação energética dos animais em pastagem cultivada de inverno é uma alternativa economicamente viável para recria de fêmeas de corte visando seu acasalamento aos 14 meses de idade. Quando o objetivo é acasalamento aos 24 meses, esta prática pode ser desnecessária do ponto de vista econômico, pois somente a pastagem garantiria condições nutricionais adequadas para esta categoria no primeiro inverno pós-desmama.

\section{Literatura Citada}

ANUALPEC. Anuário estatístico da pecuária brasileira. São Paulo: Ed. Argos Comunicação, 2000. 216p.

FLOSS, E.L. Manejo forrageiro da aveia (Avena sp.) e azevém (Lolium sp.) In: SIMPÓSIO SOBRE MANEJO DA PASTAGEM, 9., 1988, Piracicaba. Anais... Piracicaba: Fundação de Estudos Agrários Luiz de Queiroz, 1988. p.231-268.

FRIZZO, A.; ROCHA, M.G.; RESTLE, J. et al. Suplementação energética na recria de bezerras de corte mantidas em pastagem de inverno. Revista Brasileira de Zootecnia, v.32, n.3, p.643-652, 2003.

KAMINSKI, J. Acidez do solo e a fisiologia das plantas. In: SEMINÁRIO DE CORRETIVOS DA ACIDEZ DO SOLO, 2., 1989, Santa Maria. Anais... Santa Maria: Universidade Federal de Santa Maria, 1989. p.39-61.

LOBATO, J.F.P. Sistemas intensivos de produção de carne bovina: 1. cria. In: SIMPÓSIO SOBRE PECUÁRIA DE CORTE, 4., 1997, Piracicaba. Anais... Piracicaba: Fundação de Estudos Agrários Luiz de Queiroz, 1997. p.161-204.

MORAES, A.; MARASCHIN, G.E.; NABINGER, C. Pastagens nos ecossistemas de clima subtropical. In: SIMPÓSIO SOBRE PASTAGENS NOS ECOSSISTEMAS BRASILEIROS, 1995, Brasília. Anais... Brasília: Sociedade Brasileira de Zootecnia, 1995. p.147-200.

MORAES, A.; LESAMA, M.F.; ALVES, S.J. Lavoura-pecuária em sistemas integrados na pequena propriedade. In: ENCONTRO LATINO AMERICANO SOBRE PLANTIO DIRETO NA PEQUENA PROPRIEDADE, 3., 1999, Pato Branco. Anais... Pato Branco: CEFET, 1995. p.135-139.

MSD AGVET. Improved reproductive performance in heifers. New Jersey: Merck e Co., 1992. 54p.

PHILLIPS, C.J.C. The use of conserved forages as a supplement for grazing dairy cows. Grass and Forage Science, v.43, n.1, p. 215-230, 1988.

PILAU, A.; ROCHA, M.G.; RESTLE, J. et al. Recria de bezerras de corte em pastagem de aveia preta "Avena strigosa" Schreb. mais azevém "Lolium multiflorum" Lam. In: REUNIÃO ANUAL DA SOCIEDADE BRASILEIRA DE ZOOTECNIA, 38., 2002, Recife. Anais... Recife: Sociedade Brasileira de Zootecnia, [2002]. CD-ROM. Forragicultura. FOR-1010.

POPPI, D.P.; McLENNAN, S.R. Protein and energy utilization by ruminants at pasture. Journal of Animal Science, v.73, n.1, p.278-290, 1995.

PÖTTER, L. Curso de sistemas de produção. Santa Maria: Curso de Pós-graduação em Zootecnia, 1998. 15p.

PÖTTER, L.; LOBATO, J.F.P.; MIELITZ NETTO, C.G.A. Análises econômicas de modelos de produção com novilhas de corte primíparas aos dois anos, três e quatro anos de idade. Revista Brasileira de Zootecnia, v.29, n.3, p.861-870, 2000.

QUADROS, F.L.; MARASCHIN, G.E. Desempenho animal em misturas de espécies forrageiras de estação fria. Pesquisa Agropecuária Brasileira, v.22, n.5, p.535-541, 1987.

REARTE, D.H. Sistemas pastoriles intensivos de produccion de carne de la region templada. In: REUNIÃO ANUAL DA SOCIEDADE BRASILEIRA DE ZOOTECNIA, 36., 1999, Porto Alegre. Anais... Porto Alegre: Sociedade Brasileira de Zootecnia, 1999. p.213-223.

RESTLE, J.; LUPATINI, G.C.; VALENTE, A.V. et. al. Avaliação da mistura de aveia preta (Avena sativa) e azevém (Lolium multiflorum) sob pastejo submetida a níveis de 
nitrogênio. Produção Animal. In: REUNIÃO ANUAL DA SOCIEDADE BRASILEIRA DE ZOOTECNIA, 30., Juiz de Fora. Anais... Juiz de Fora: Sociedade Brasileira de Zootecnia, 1993. p.71.

ROCHA, M.G. Desenvolvimento e características de produção de novilhas de corte primíparas aos dois anos de idade. Porto Alegre: Universidade Federal do Rio Grande do Sul, 1997. 247p. Tese (Doutorado em Agronomia-Zootecnia) - Universidade Federal do Rio Grande do Sul, 1997.

ROCHA, M.G.; RESTLE, J.; PILAU, A. et al. Produção animal e retorno econômico da suplementação em pastagem de aveia e azevém. Ciência Rural, v.33, n.3, p.200-205, 2003.

ROCHA, M.G.; RESTLE, J.; FRIZZO, A. et al. Alternativas de utilização da pastagem hibernal para recria de bezerras de corte. Revista Brasileira de Zootecnia, v.32, n.2, p.383-392, 2003a.

ROCHA, M.G.; RESTLE, J.; HOFFMANN, W.C. et al. Sistemas de utilização da pastagem para acasalamento de terneiras de corte com um ano de idade. In: REUNION LATINOAMERICANA DE PRODUCIÓN ANIMAL, 2001, Ciudad de Havana. Anais... Ciudad de Havana: ALPA, 2001. p.1543-1544.

ROLAS. Recomendações de adubação e de calagem para os estados do Rio Grande do Sul e de Santa Catarina. 4.ed. Pelotas: 1999. 223p.
ROSO, C.; RESTLE, J. Aveia preta, triticale e centeio em mistura com azevém. 2. Produtividade animal e retorno econômico. Revista Brasileira de Zootecnia, v.29, n.1, p.85-93, 2000.

ROVIRA, J. Reproduccion y manejo de los rodeos de cria. Montevideo: Hemisferio Sur, 1974. 293p.

SIQUEIRA, O.J.F. Resposta das culturas à calagem e a fósforo em solos do Rio Grande do Sul e de Santa Catarina e seus reflexos técnicos-econômicos. In: SEMINÁRIO DE CORRETIVOS DA ACIDEZ DO SOLO, 2., 1989, Santa Maria. Anais... Santa Maria: Universidade Federal de Santa Maria 1989. p.151-176.

SOARES, A.B.; RESTlE, J. Produção animal e qualidade de forragem de pastagem de triticale e azevém submetida a doses de adubação nitrogenada. Revista Brasileira de Zootecnia, v.31, n.2S, p.908-917, 2002.

ZIMMER, A.H.; EUCLIDES FILHO, K. As pastagens e a pecuária de corte brasileira. In: SIMPÓSIO INTERNACIONAL SOBRE PRODUÇÃO ANIMAL EM PASTEJO, 1997, Viçosa, MG. Anais... Viçosa, MG: Universidade Federal de Viçosa, 1997. p.349-380.

Recebido em: 09/07/02

Aceito em: 13/12/02 